\title{
Genotoxic and Carcinogenic Effects of Methyl Isocyanate (MIC) Reviewed on Exposed Bhopal Population and Future Perspectives for Assessment of Long-Term MIC-Effect
}

Bani Bandana Ganguly ${ }^{1^{\star}}$, Shouvik Mandal ${ }^{1}$ and Nitin N Kadam ${ }^{2}$

${ }^{1}$ MGM Center for Genetic Research \& Diagnosis, MGM New Bombay Hospital, Navi Mumbai, India

${ }^{2}$ Department of Pediatrics, MGM Medical College, Navi Mumbai, India

\begin{abstract}
MIC disaster has been established as one of the largest industrial disasters which claimed $>10000$ lives and seriously jeopardized lives of millions. Besides acute illness and multi-system complications, genetic damage at chromosomal level was indicative of long-term illness as demonstrated in individual reports. Presence of self-replicating minutes detected after 1114 days indicated persistence of rearrangements in the exposed individuals. Among the systemic complications, respiratory, ophthalmic and reproductive systems were significantly affected then and now. Some of the females with elevated chromosome abnormalities had history of fetal loss and high incidence of perinatal and neonatal mortality. Several in vivo and in vitro experiments concluded that MIC may exert geno-toxicity by binding of carbamoylating agents to nuclear proteins. The cancer-incidence among the MIC-exposed survivors is calculated from hospital records. Moreover, continuous soil contamination by multiple of chemical wastes in the site might have augmented the genetic changes through interaction with other biologic and a-biologic factors. Owing to variable latency period of chemicals, and also unavailability of genetic information measured in stratified cohorts immediately after the disaster, it is worthy of screening genetic condition in the exposed survivors and their progenies, though 32 years have gone. This review further pays importance to compounding effects of multiple confounding variables on the exposed individuals. Nevertheless, comparison of a current genetic screening with the previous genetic condition would actually discuss about the long-term genotoxic effect of MIC on Bhopal population; however, such exercise would not be a straightforward approach due to interaction of several confounders.
\end{abstract}

Keywords: Methyl isocyanate (MIC) disaster in Bhopal; Systemic complications; Genetic alterations; Cancer incidence; Future perspectives

\section{Introduction}

"Who is interested about the old disasters? Anyone who works in the process safety field" answered by Ronald J Willey [1]. He stated "as if time has stood still since $1984 \ldots$ all of the safety systems are not effective if management is not alert enough... prevention of victims of course, but also focus on victims after the event. That is an important responsibility that must be taken seriously". Methyl isocyanate (MIC) gas-leak from Union Carbide India Limited (UCIL) factory on 2-3 December 1984 in Bhopal, India has claimed to be the world's worst industrial disaster for killing over 10000 people in its immediate aftermath and causing multisystemic injuries to over 500000 people for decades [2]. Introduction of $\sim 500$ liter water into MIC storage tank no. E610 resulted in uncontrolled exothermic reaction with release of $>41$ ton of MIC into the atmospheric environment in the midnight of December 2, 1984. The safety system was on stand-by (a caustic scrubbing tower) or out-of-service (a flare tower). Thus the mitigation of external release of MIC failed allowing expulsion of MIC 35 meters from ground level for $\sim 15-30$ minutes. In that winter night the atmospheric temperature was $\sim 8-10^{\circ} \mathrm{C}$ with the thick winter-fog settled at ground level. The gas cloud infiltrated the surrounding densely populated residential areas of poor Shanties and flew towards the city center located to the south of UCIL at a windspeed of $10-12 \mathrm{~km} / \mathrm{hr}$. The direction of gas-spread was largely followed the direction of atmospheric wind in south west direction. People were asleep, wrapped in quilts in closed rooms; however, woke up with severe breathlessness and coughing, and acute burning of eyes, and tumbled out of their houses where a dense cloud of more gas killed many people instantly by blocking the airway passage. The survivors suffered with eye opacity, burning and watering; bleeding through mouth, eyes and ears; chronic breathlessness and coughing; and multiple systemic and psychiatric complications [2]. In fact 'lucky were those who died immediately', and thus that night were 'fateful' for the deceased. A cohort of 82,021 individuals in 36 municipal wards were classified with severe, moderate and mild exposure and another cohort of 15,931 people from unexposed areas were registered for conducting survey of health effects followed by MIC exposure. Much of the discussion on the disaster has been reported elsewhere [3-7]. Most of the information on the medical consequences of the Union Carbide disaster in Bhopal has been generated by the Indian Council of Medical Research (ICMR) [2].

Several safety flaws were demonstrated to be the cause of the accident. The management decisions on saving operating expenses had led the scrubber system on stand-by, flare system defunct and removal of coolant from the refrigeration of MIC storage tank, besides inadequate emergency management due mainly to lack of knowledge on potential toxic impact of MIC on the human health [8]. MIC was used as an ingredient for manufacturing pesticides in this Bhopal-based plant. There was no data available on the extent of its toxicity except a publication of 1964, and no antidote provided by the agency for accident management and/or occupational safety measure [9]. In fact the gas

*Corresponding author: Bani Bandana Ganguly, MGM Center for Genetic Research \& Diagnosis, MGM New Bombay Hospital, Vashi Sector 3, Navi Mumbai 400703, India, Tel: 9122 61526527; E-mail: mgmgeneticlab@yahoo.com, bani.b.ganguly@gmail.com

Received March 13, 2017; Accepted March 25, 2017; Published April 04, 2017

Citation: Ganguly BB, Mandal S, Kadam NN. (2017) Genotoxic and Carcinogenic Effects of Methyl Isocyanate (MIC) Reviewed on Exposed Bhopal Population and Future Perspectives for Assessment of Long-Term MIC-Effect. J Environ Anal Toxicol 7: 452. doi: 10.4172/2157-7048.1000452

Copyright: ( 2017 Ganguly BB, et al. This is an open-access article distributed under the terms of the Creative Commons Attribution License, which permits unrestricted use, distribution, and reproduction in any medium, provided the original author and source are credited. 
Citation: Ganguly BB, Mandal S, Kadam NN. (2017) Genotoxic and Carcinogenic Effects of Methyl Isocyanate (MIC) Reviewed on Exposed Bhopal Population and Future Perspectives for Assessment of Long-Term MIC-Effect. J Environ Anal Toxicol 7: 452. doi: 10.4172/21610525.1000452

Page 2 of 10

released was not just MIC alone, but a number of by-products generated such as hydrogen cyanide, nitrogen oxides, carbon monoxide, phosgene, mono-methylamine and many other contaminants through exothermic reaction with water and atmospheric air and moisture. Exothermic reaction of MIC leads to its degradation and conversion to hydrogen cyanide $(\mathrm{HCN})$ at $\sim 200^{\circ} \mathrm{C}$, which was evidenced in cherry red color in blood and in the viscera of some of the victims indicating acute cyanide poisoning [2].

Bhopal Gas Disaster was totally a new experience for the entire medical community. As no specific antidote to the toxic gases was known, the management was totally on empirical basis, though many survivors responded well to sodium thiosulphate treatment, an effective antagonist for cyanide poisoning but not for MIC [10], which was initially recommended by Union Carbide Corporation (UCC) but denied later. As $62.6 \%$ of the total population was affected, it was expected that a large number of survivors would suffer from multisystem morbidity. Total lack of knowledge regarding the biological effects of the offending chemical raised several pertinent questions concerning long term effects and genetic defects in children born to exposed mother. Ironically, there was no prior awareness or information regarding MIC toxicity neither with the public nor with the authorities who should have known about this. The preliminary experimental toxicity study carried out by Kimmerle and Eben [11] on 4 human volunteers exposed for 1-5 min revealed: $0.02 \mathrm{ppm}$-no symptoms; $2-4 \mathrm{ppm}$-increased irritation of eyes, lacrimation, cough, chest pain, dyspnea; and $21 \mathrm{ppm}$-unbearable symptoms. A very similar pattern of symptoms was seen in the exposed population [11].

Initial autopsy revealed a characteristic cherry red discoloration of lungs alongside massive pulmonary edema, emphysema, hemorrhages, visceral congestion, cerebral edema and anoxic brain damage as acute effect of gas exposure [2]. The sub-acute phase was characterized by persistent morbidities caused by inhalation of gas amongst survivors of acute phase. The chronic effect was documented by a large number of study groups initiated by government and non-government organizations in vivo and in vitro in different organisms across the world [9]. Survivors continue to experience high incidence of reported health problems including febrile illnesses, respiratory, neurologic, psychiatric and ophthalmic symptoms. Clinical studies have shown chronic illness including breathlessness, pulmonary fibrosis, bronchial asthma, chronic obstructive pulmonary disease, recurrent chest infections, keratopathy and corneal opacities in exposed cohorts. Loss of appetite, menstrual irregularities, recurrent fever, persistent cough, neurological disorders, fatigue, weakness, anxiety and depression persisted among the most common symptoms. The systemic complications in acute and chronic phase among MIC-exposed population and in experimental animals have been summarized in Table 1 .

In a preliminary epidemiological survey of the effect of the Bhopal accident on pregnant women living adjacent to the facility, Varma $[12,13]$ reported a very high rate of unsuccessful pregnancies and a higher than normal infant mortality during the first 30 days of life. The data collected on 2566 pregnant and exposed women revealed a significant amount of pregnancy loss (18\%), including 373 (15\%) abortions and 82 (3\%) stillbirths. The mothers (no.30) who were exposed in the first trimester of their pregnancy delivered with congenital malformations [2,14]. A larger study involving 18,978 exposed and 13,539 unexposed households presented a manifold increase in perinatal and neonatal mortality rates in women who had last menstrual period (LMP) before November 18, 1984 [3]. In vivo animal experiments also showed similar pregnancy outcome with fetal loss and intrauterine growth retardation
(IUGR) [15-17]. Short exposure of pregnant mice to near lethal concentrations caused the loss of total litters, and longer exposures to lower concentrations of MIC resulted in decreased litter size at birth, and a higher rate of neonatal mortality [15]. MIC-exposure related maternal hormonal changes and hypoxia, and teratogenic and fetotoxic effects of MIC were the causes of fetal and neonatal malformations [18]. However, more detailed investigation was recommended on this population as well as in vitro to conclude whether the effect was due to selective toxic effect of MIC on the fetus, or a manifestation of maternal toxicity since evidence of significant teratogenicity was not found, nor did there appear to be effects on fertility of exposed mice.

Following MIC-accident, extensive investigation was carried out in different living systems on different parameters and published in Environmental Health Perspectives [19]. The reactivity of isocyanates with specific functional groups on proteins was extensively examined by Brown et al. [20]. The reactions of MIC with non-essential functional groups and the highly exothermic hydrolysis reaction would both act to compete with an interaction with specific enzymes or proteins during inhalation exposures. However, the modification of functional groups can apparently lead to antibody-formation as shown by Karol and coworkers in experimental animals and in survivors of the Bhopal accident [21]. However, the significance of these findings in relation to the overall health effects of MIC exposure will require further study.

In summary, the principal findings of the ICMR was documented as the toxins from UC factory have crossed into the blood stream of those exposed and have caused damage to the lungs, brain, kidneys, muscles as well as gastro-intestinal, reproductive and immune systems [2]. The toxins have also crossed the placental barrier leading to fetal poisoning [22]. Of the patients treated at the Hamidia hospital, Bhopal immediately after the disaster, $98.9 \%$ suffered breathlessness, $85.8 \%$ had eye problems, $91 \%$ had gastro-intestinal problems, and in varying degrees, there were at least 16 other complications involving other organs. More than ten of these symptoms persisted among the survivors till as late as 1992 (when the last ICMR report was published) with the addition of menstrual irregularities, spontaneous abortions and neurological and mental health problems $[2,23]$. Six-monthly morbidity surveys from 1987 to 1991 demonstrated an increasing trend of the number of people with exposure-related symptoms. According to one study there were three times more people with respiratory symptoms in 1991 as compared to 1987 [2].

\section{Genetic Damage in The Gas-Victims}

Following MIC-exposure, genetic damage in Bhopal population was a serious concern. Genetic alteration could increase cancer-risk and multi-factorial morbidities, disturb immune system, and physical and mental retardation in offspring of the next generation. A multicenter program was conducted by Indian Council of Medical Research (ICMR) for screening of genetic damage in MIC-exposed population, which unfortunately has not been reported yet to the public but likely to be available soon. All genetic studies were carried out in peripheral lymphocytes with a view to evaluating MIC-induced chromosomal alterations as guided by EHC [24,25]. The author had studied over 1000 individuals from different distances from UCIL plant from which an excerpt of the data on 129 individuals was reported [26].

\section{Chromosome aberrations (CA)}

Genetic damage in human lymphocytes was measured on MICexposed population immediately after the accident by Goswami [27], Deo et al. [28], Saxena et al. [29] and later by Ghosh et al. [26]. Goswami 
Citation: Ganguly BB, Mandal S, Kadam NN. (2017) Genotoxic and Carcinogenic Effects of Methyl Isocyanate (MIC) Reviewed on Exposed Bhopal Population and Future Perspectives for Assessment of Long-Term MIC-Effect. J Environ Anal Toxicol 7: 452. doi: 10.4172/21610525.1000452

Page 3 of 10

Table 1: Systemic complications in MIC-exposed Bhopal population: Acute and chronic phases.

\begin{tabular}{|c|c|c|c|c|c|c|}
\hline & Respiratory & Ophthalmic & Skin & GI & Neuro/psycho & Reproductive \\
\hline $\begin{array}{l}\text { Immediate: } \\
\text { Acute }\end{array}$ & $\begin{array}{l}\text { +++ (>98\%) } \\
\text { Acute breathlessness/cough/chest pain/ } \\
\text { chocking. Immediate chest radiographs } \\
\text { highlighted alveolar lesions. Obstructive } \\
\text { airway passage, progression of } \\
\text { lesions in lungs, necrotizing lesions } \\
\text { affecting bronchioles/alveoli, } \\
\text { capillaries with excessive fluid flow } \\
\text { into alveoli. Interstitial fibrosis and } \\
\text { bronchiolitis obliterans, necrotic } \\
\text { epithelial debris in alveoli and } \\
\text { bronchioles were predominant in } \\
\text { autoposies. 55\% elevated levels } \\
\text { of Carboxyhaemoglobin, and } \\
\text { Methaemoglobin. }\end{array}$ & $\begin{array}{l}\text { (>++ } \\
\text { (>98\%) } \\
\text { Lacrimation, } \\
\text { photophobia, } \\
\text { profuse lid } \\
\text { oedema, corneal } \\
\text { ulcerations, foreign } \\
\text { body sensation, } \\
\text { chilli burning, and } \\
\text { blurring of the } \\
\text { vision }\end{array}$ & $\begin{array}{l}\text { + Dermal } \\
\text { sensitization }\end{array}$ & \begin{tabular}{|c|}
\multicolumn{1}{c|}{} \\
$92 \%$ \\
loss of \\
appetite, $52 \%$ \\
nausea, $82 \%$ \\
vomiting, $80 \%$ \\
techypnoea, \\
$54 \%$ \\
tachycardia, \\
$2 \%$ had fever.
\end{tabular} & $\begin{array}{c}+++(>98 \%) \text { Weakness, tremors, } \\
\text { tetany, hypersomnolence, neurotic } \\
\text { depression, anxiety. Children } \\
\text { born to exposed parents appeared } \\
\text { disobedient/stubborn (4.36\%), tremor } \\
\text { tentrum }(4.36 \%) \text {, mental retardation } \\
(2.3 \%) \text { and delayed/poor development } \\
\text { of speech, lower intellectual levels; } \\
\text { exposed children suffered from } \\
\text { mental health }\end{array}$ & $\begin{array}{l}\text { Irregular menstrual } \\
\text { cycle, leucorrhoea and } \\
\text { dysmenorrhoea. } 44- \\
48 \% \text { did not deliver a } \\
\text { live child, miscarriage } \\
\text { at first }(58.8 \%), \text { second } \\
(42.1 \%) \text { or third } \\
(40.1 \%) \text { trimester }\end{array}$ \\
\hline $\begin{array}{l}\text { Long term: } \\
\text { Chronic }\end{array}$ & $\begin{array}{l}\text { ++ } \\
\text { 3-year post disaster lung biopsy } \\
\text { revealed bronchiolitis obliterans in } \\
\text { fairly large sized terminal bronchioles, } \\
\text { subpleural/septal fibrosis, interstitial } \\
\text { aggregates, compensatory } \\
\text { emphysema, bronchiolitis and } \\
\text { peribronchial and perivascualar fibrosis. } \\
\text { Broncho-alveolar lavage study revealed } \\
\text { alveolar macrophages and neutrophils } \\
\text { in lower respiratory tract (highly } \\
\text { prevalent among smokers) along with } \\
\text { elevated levels of fibronectin indicating } \\
\text { fibrosis of lung parenchyma and } \\
\text { bronchial asthma, and hypersensitivity } \\
\text { to pneumonitis. }\end{array}$ & \begin{tabular}{|c|}
++ \\
Photophobia, \\
conjunctival and \\
circumcorneal \\
congestion with \\
relatively little \\
oedemaa, corneal \\
ulcer, cataract \\
(polychromatic \\
lusture), burning \\
and watering \\
sensation, sign of \\
red eye, superficial \\
interpalpabral \\
erosions, corneal \\
opacity, discharge \\
and fundal \\
changes
\end{tabular} & $\stackrel{+}{+}$ Not detailed & \begin{tabular}{|c|}
+ \\
Renal failure/ \\
Chronic kidney \\
disease \\
increased \\
significantly (? \\
excessive use \\
of drugs by \\
gas exposed \\
population \\
for their \\
morbidities)
\end{tabular} & $\begin{array}{l}\text { ++ } 75 \% \text { psychiatric morbidities: } \\
\text { muscle weakness, poor memory, } \\
\text { neurotic depression, emotional } \\
\text { disturbance visual perceptual and } \\
\text { attention/response speed along with } \\
\text { attention/vigilance were severely } \\
\text { affected; cognitive impairment; } \\
\text { traumatic stress disorder, pathological } \\
\text { grief reaction, emotional reaction } \\
\text { to physical problems; depressive } \\
\text { neurosis. In 1994, epidemiological } \\
\text { and clinical studies conducted by } \\
\text { International Medical Commission } \\
\text { reported: } 7.27 \% \text { suffered with current } \\
\text { post traumatic stress disorder and } \\
15.19 \% \text { suffered with life time post } \\
\text { traumatic stress disorder. }\end{array}$ & $\begin{array}{c}\text { Fetal loss } 26.3 \% \\
\text { compared to } 7.8 \% \text { in } \\
\text { control; } \\
5-6 \text { times higher infant } \\
\text { mortality within } 30 \\
\text { days of birth; } \\
\text { increased perinatal } \\
\text { and neonatal mortality } \\
\text { studied in } 18,978 \\
\text { households: } \\
12.1 \% \text { died within } \\
30 \text { days; } 10 \% \text { died } \\
\text { at }<5 y \text { ys with high } \\
\text { morbodity of } 200 \\
\text { children evaluated in } \\
1990 \text { of } 273 \text { surviving } \\
\text { children born to } \\
\text { exposed parents. }\end{array}$ \\
\hline $\begin{array}{l}\text { Experimental } \\
\text { animals }\end{array}$ & $\begin{array}{c}\text { F334/N rats and B6C3F1 mice } \\
\text { exposed to } 30 \text { ppm of MIC developed } \\
\text { obstructive lung disease, peribronchial } \\
\text { and intra luminal fibrosis, fibrosis } \\
\text { of major bronchi, acute to chronic } \\
\text { bronchitis, chronic alveolitis, atelectasis } \\
\text { and obstructive airway lesion }\end{array}$ & $\begin{array}{c}\text { Cataract formation } \\
\text { in young rat lenses } \\
\text { incubated in } 50 \\
\text { mmol/L MIC; } \\
\text { no irreversible } \\
\text { damage in Fischer } \\
\text { rats exposed to } \\
\text { 3-30 ppm for } 2 \text { hrs }\end{array}$ & Not detailed & Not detailed & $\begin{array}{l}\text { Ischemia of rat brain leading to } \\
\text { cerebral hypoxia; growth of muscle } \\
\text { fibers and death of fibroblast and } \\
\text { myoblasts in rats; higher doses } \\
\text { caused muscle aches and repeated } \\
\text { episodes of extreme muscular } \\
\text { weakness; persistent muscle } \\
\text { weakness, lasting from } 1-60 \text { months } \\
\text { following exposure to CO }\end{array}$ & $\begin{array}{l}2-5 \text { ppm exposure } \\
\text { reduced foetal and } \\
\text { placental weight; } \\
\text { complete loss of } \\
\text { all fetuses in mice } \\
\text { exposed to } 9 \text { and } 15 \\
\text { ppm for } 3 \mathrm{~h} ; 0,1,3 \\
\text { ppm/ } 6 \text { hrs/day during } \\
14-17 \mathrm{~d} \text { gestation } \\
\text { lowered survival in } \\
\text { Swiss (CD-1) mice; } \\
\text { inhalation of } 1.3 \mathrm{ppm} / 6 \\
\text { hrs/day for } 4 \text { days to } \\
\text { mice of both sexes } \\
\text { revealed no effect on } \\
\text { mating/fertility after } \\
1 / 8 / 17 \text { weeks post } \\
\text { exposure }\end{array}$ \\
\hline
\end{tabular}

reported a higher frequency of chromosome aberrations (CA) and sister chromatid exchanges (SCEs) in MIC-exposed individuals compared to controls [27]. SCE frequencies were tripled in MIC-exposed persons in that study. The result was compared to two groups of controls (one group comprising persons present in the same house; the second group of persons were chosen from distant places, $20-50 \mathrm{~km}$ away from the incident-site. Chromosomal breaks have been observed in 10 out of 14 MIC-affected people (71.4\%) studied while only 6 out of $28(21.4 \%)$ controls had chromosomal aberrations. Some MIC-exposed persons had chromatin bodies in addition to the normal 46 chromosomes. These observations suggest that chromosomal DNA has been damaged. Significant degree of chromosomal aberrations was reported two and half months post disaster, however, no increase in chromosome aberrations was reported by other studies [27].

Deo et al. also reported increased chromosomal aberrations in MIC-exposed cases when compared to controls obtained from Mumbai, a different socio-economic stratum [28]. Ghosh et al. [26] assessed frequencies of $\mathrm{CA}, \mathrm{SCE}$, and replicative index following peripheral blood lymphocyte culture in 129 individuals (83 exposed: 40 male and 43 female, and 46 unexposed from Bhopal) from Bhopal, 1114 days after the disaster. CA was recorded in first cycle metaphases (M1) and SCEs at second mitotic cycle (M2), following standard phytohemagglutinin (PHA)-stimulated blood culture protocol [30]. The frequency of CA, in general, was higher in individuals from the exposed populations, and that was predominant in females. Nondisjunction of chromosomes or laggard was rare resulting in absence of aneuploidy. The persistence of CA in the form of replicating double minutes and exchange configurations, even 1114 days post-exposure to MIC, indicated a residual effect on T-cell precursors [26]. None of them had been exposed to any other known clastogenic agents except a single chest X-ray. Majority of the recruited females were housewives and the males were day-labors. Because the lesions induced by chemicals are mostly S-dependent for expression in subsequent divisional cycle, the damaged T-lymphocytes may remain circulating 
Citation: Ganguly BB, Mandal S, Kadam NN. (2017) Genotoxic and Carcinogenic Effects of Methyl Isocyanate (MIC) Reviewed on Exposed Bhopal Population and Future Perspectives for Assessment of Long-Term MIC-Effect. J Environ Anal Toxicol 7: 452. doi: 10.4172/21610525.1000452

for long periods, and these aberrations can be observed only if the cells are stimulated to divide in vitro [25]. Such findings on CA suggest that the future generations of the survivors might possibly carry the effects of the leftovers of the industrial toxins. Therefore, it is evidenced that MIC can establish some genetic effect on T-cell precursors; however, the knowledge about the extent of genetic alterations and their clinical impact is very meager. The spectrum of SCEs in Ghosh et al. [26] study could not be correlated to exposure status or sex, which was in agreement with others [28]. However, elevated SCEs were reported by Goswami [27] and Mason et al. [31]. Depression of mitotic (MI) and replicative indices (RI) in Ghosh et al. [26] study was not consistent with MIC-exposure in Bhopal population, which was consistent with Conner et al. [32] in murine alveolar macrophages. However, delayed cell cycle was reported by Deo et al. [28] in peripheral lymphocytes of the MIC-exposed people, and also in experimental animals [33].

An extremely important concern was the possibility that MIC exposure might lead to genetic damage in the MIC-exposed Bhopal population. MIC was tested for genotoxic potential in a variety of in vitro and in vivo assays by Shelby and other groups [31, 34, 35]. They have reported negative results in Salmonella/mammalian microsome assay in five bacterial strains in a pre-incubation protocol, and Drosophila sex linked recessive lethal test. Mutagenic expression was also tested in urine of the exposed individuals [28], which did not reveal any mutation. Reproducible dose related increase in both SCE and chromosome aberrations were reported in Chinese Hamster Ovary $(\mathrm{CHO})$ cells with or without metabolic activation in vitro [35]. In mice, a single $2 \mathrm{~h}$-exposure to concentrations upto $30 \mathrm{ppm}$ by inhalation didn't induce chromosome aberration in bone marrow; however, cell cycle was delayed significantly. In other experiments involving exposure on 4 consecutive days to a maximum dose of $6 \mathrm{ppm}$ resulted in significant delay in cell cycle and increased SCE and chromosome aberration in bone marrow cells, and a dose-dependent increase in SCE in cultured lung cells from mice exposed to 1,3 , or 6 ppm MIC but not in peripheral blood lymphocytes of mice exposed to concentrations as high as $6 \mathrm{ppm}$ [34]. When micronuclei $(\mathrm{MN})$ was considered as indicator of genotoxic potential of MIC, a significant dose-dependent depression of polychromatic erythrocytes was demonstrated but no increase in frequencies of micronucleated polychromatic erythrocytes and micronucleated normochromatic erythrocytes were reported in bone marrow and peripheral blood samples of mice [36]. No micronucleus was observed in 7 and 14 days post-exposure in bone marrow of rats exposed to MIC by inhalation. However, a significant increase in micronucleated polychromatic erythrocytes was observed in peripheral blood of male mice in one experiment. Genotoxic/ cytotoxic effect was evidenced through depression in bone marrowcellularity in animals exposed by inhalation [33]. Genotoxic response of MIC-modified DNA described decrease in plaque formation in E. coli. [37]. Collectively, in vivo and in vitro geno-toxicity studies concluded that MIC has clastogenic potential.

The studies concluded that MIC may exert genetic toxicity by binding of carbamoylating agents to nuclear proteins. From these results and from considerations of the chemistry of isocyanate-DNA and isocyanate-protein reactions, it was speculated that MIC may exert its genotoxic activity through interactions with proteins affecting chromosomal structure, rather than through direct genetic mutations.

Plausible artifacts were indicated as MIC-induced CA: undue overestimation: Genetic damage in Bhopal-exposed population at chromosomal level was first published by Goswami [27]; however, the figures indicated as aberrations were purely artifacts. In fact, the metaphases were scratched due to unsafe handling of glass slides. Deo et al. [28] conducted chromosomal analysis on people admitted in Hamidia Hospital in Bhopal and from Railway colony within 2-3 weeks after exposure where controls (very few) were selected mostly from Mumbai, a different socioeconomic group. The data documented was not uniformly collected with number of cells ranging from 6-271, which indicated inconsistency in culture outcome. Mean data was poorly documented with high standard deviation. The paper has not addressed the possible consequences at cellular or genetic level. In a later publication by Goswami et al. [38], the result was highly criticized by scientific fraternity and recommended withdrawal from the journal [39]. The figures showing Robertsonian translocations are simply association of acrocentric chromosomes, and the metaphase with arrowed chromosomes are not showing any deletion. Chromosome identification was not correct as one chromosome \#11 was labeled as chromosome \#5. Giemsa banding was of substandard quality and not appreciable for chromosome-classification. It is surprising that the Human Genetics journal had reviewed and published the articles of Goswami [27, 38]. Another publication by Ghosh et al. [26] documented chromosomal aberrations including self-replicable double minutes, breaks, gaps, dicentrics, rings and tri- and quadriradial chromatid exchanges etc., and SCEs on 129 MIC-exposed individuals 1114 days post exposure, which were more pronounced in females. Mishra et al. [40] reported genomic instability in human colon epithelial-FHC cells exposed to MIC in vitro. However, G-banded karyotypic analysis appears to be very poor with a possibility of false positive results as chromosome with overlapped chromatids was described as a dicentric chromosome by Mishra and his group [40].

In all, the data on abnormalities was collected following solidstaining, wherein G-banding would have facilitated recognition of translocations and other stable rearrangements (inversions, deletions, duplications, etc). Nevertheless, presence of self-replicating minutes after 1114 days of the incident in Ghosh et al. report may indicate risk of transmissible and heritable rearrangements in the population [26].

To address the long-term genotoxic effects among the survivors, Malla et al. [41] reported the frequency and pattern of chromosome instability through conventional chromosome aberration assay in the peripheral blood of exposed individuals to unveil the longterm genotoxicity of the exposure. Considering fragments solely as chromosome type and terminal deletions as chromatid type aberrations raise question on the accuracy of the data collected and interpretation drawn on the result, which could have been supported partly by figures or images of aberrant cells; however, no figures have been included for understanding the classification. Discussion on preponderance of aberrations in males and the result on pedigrees are also missing completely. However, their result collected during 20082011 has indicated long-term genetic effects induced by MIC-exposure in 1984 in $100 \%$ of exposed cases studied. The prevalence of genetic abnormalities in $100 \%$ cases after 27 years from the disaster has not been discussed with sufficient information. The same group, after reporting chromosome data, has reported micronuclei frequency in MIC exposed population as an indicator of cancer incidence; however, the report has not stated the incidence of cancer in their hospital registry [42].

There was a great deal of variation in study design, sample selection, selection of assay systems and parameters, and most importantly use of validated protocol and interpretative comments of the result. The MIC disaster had actually sensitized the global scientific fraternity for estimation of MIC-toxicity and associated health-risk. The data collected on exposed individuals did not follow any harmonized protocol for 
Citation: Ganguly BB, Mandal S, Kadam NN. (2017) Genotoxic and Carcinogenic Effects of Methyl Isocyanate (MIC) Reviewed on Exposed Bhopal Population and Future Perspectives for Assessment of Long-Term MIC-Effect. J Environ Anal Toxicol 7: 452. doi: 10.4172/21610525.1000452

study design and assay system, and also for eliminating the impact of the confounders. Although, a multi-center genetic investigation was carried out by ICMR following unified protocol, the result has not been made public till date. However, after three decades, some of the records have been retrieved by the author, which are presently under analysis for reporting, and will be published shortly. It is noteworthy that the author was one of the participants of that genetic survey program.

\section{Carcinogenic potential of MIC}

Carcinogenic potential of MIC in exposed individuals were documented by a number of institutions [43,44]. Analysis of a population-based cancer registry in Bhopal revealed a relative cancer risk of 1.4, 1.3 and 0.7 for lung, oropharynx and buccal cavity respectively, after adjustment with age and tobacco consumption. ICMR's cancer registry reported higher incidence of tongue, mouth, hypopharynx, oesophagus and lung cancer in affected areas compared to unaffected ones; however, adjustment of tobacco consumption neutralized the cancer incidence between the exposed and unexposed groups. ICMR's conclusion could not resolve the issue of tobacco consumption in unexposed areas. Several broadcasting media stated that cancer cases in Bhopal have more than tripled among men and more than doubled among women between 1988 and 2007. A study conducted at Jawaharlal Nehru Cancer Hospital and Research Centre, Bhopal also demonstrated an increase in the incidence of cancer in the exposed population. However, correlation with the life-style and other biological factors may reduce the risk of malignancy induced solely by MIC-exposure decades after the exposure. Nevertheless, MIC has not been classified as carcinogen by International Agency for Research in Cancer (IARC) and US-Environment Protection Agency (US-EPA) [45-47].

Cancer is a multi-step process of acquisition of somatic mutations in stem cells, and that may not be caused solely by one mutation. Rather interaction of several co-operating mutations may facilitate onset to progression of a cancer, which may happen over a period of time through clonal development and expansion [48-50]. To discuss about the carcinogenic incidence in MIC-exposed population, well defined/designed survey is essential for the affected cases to capture the interactive effects of their demographic variation, life-style, nutrition, living and work-environment, source of drinking water, and so on. Also, lack of information on baseline pre-MIC-disaster cancer prevalence in the marked municipal wards or Bhopal as a whole does not allow talking about MIC-related cancer prevalence without discussing their clinical and laboratory records. Investigation on founder and driver mutations for the most prevalent cancer in MIC-exposed Bhopal population and its correlation with other published reports could describe the MICrelated changes. However, time-gap after the disaster would certainly introduce some error due to interaction of multiple confounding factors. The reported cancer incidence did not charter about the age of onset and presence of co-morbidities since the data has mostly been retrieved from hospital records [44]. Thus, targeted screening of precancerous lesions would be meaningful for the common organs affected such as head \& neck cancer as projected in consumers of tobacco. Personal interaction with affected cases could extract some information about the preponderance of cancer in MIC-exposed population of Bhopal.

\section{Immunotoxicity of MIC}

A particular concern immediately following the accident in Bhopal was the fear that the exposed population would be unduly susceptible to disease and would suffer disproportionate morbidity from a variety of infectious agents. The immunotoxicity studies of Tucker and co- workers reported minor deficits in T-cell lymphoproliferative response and more susceptibility to influenza challenge in MIC-exposed mice [51]. Evaluation of the cellular and humoral immunity in MIC-exposed individuals had presented increased $\mathrm{T}$ cells and $\mathrm{T}_{\mathrm{H}}$ cell population and normal range of $\mathrm{B}$ cells and CD8, 4-8 weeks post exposure [28]. Significant depression in phagocytosis and T-cell rosettes were reported after 10 weeks, which indicated suppressed cell-mediated immune response among exposed individuals [29]. Reduced response to $\mathrm{T}$ and $\mathrm{B}$ cell mitogens was reported in $71 \%$ of the exposed population. Low titers of $\operatorname{IgG}, \operatorname{IgM}$ and IgE class of antibodies were noticed in $11 \%$ of the exposed cases [52]. MIC-specific antibodies were correlated with severity of lung damage [53]; though MIC didn't reveal any synergistic effect on humoral immunity in MIC-exposed protein deficient people [54]. In animal models, increased weight of liver and thymus, and impaired alveolar and peritoneal macrophage functions were described to be associated with suppression of phagocytosis of sheep erythrocytes resulting in susceptibility to bacterial E. coli endotoxin [55]. Resistance to other infections such as influenza virus, Listeria monocytogenes and mouse malaria parasite was not compromised in sheep [51]. MIC was negative in the male mouse dominant lethal assay [19]. Altogether, lowtiter and transient antibody response was noticed in exposed human and animals [21].

In vitro and in vivo tests provide convincing evidence that MIC is capable of inducing chromosomal damage and that this genetic toxicity is not strongly expressed in vivo, perhaps because of the selective reactivity of MIC with proteins [19]. Experimental studies have provided mechanistic understanding of MIC-exposure at a molecular level. Immunotoxic implications, toxico-genomic effect, inflammatory response, elicitation of mitochondrial oxidative stress, chromosomal and microsatellite instability have been studied comprehensively in cultured mammalian cells [35]. Isocyanates are able to modulate bio-molecules, resulting in a series of bio-transformations [37,56,57], which in turn may affect health adversely, yet they have a wide array of industrial applications. MIC, a reactive byproduct, is detrimental to numerous organ and its functional systems. It forms DNA cross links/adducts by reacting with exocyclic amino group of dNTPs, in turn contributing to cytotoxicity $[58,59]$. MIC intermediates (N-methylcarbamate) are also toxic to cultured mammalian cells $[53,60,61]$.

Srivastava et al. [22] stated that the long term genotoxic effects of MIC need further in-depth studies to design newer and more effective diagnostic and therapeutic strategies for helping the survivors. The paucity of data on the toxic effects of MIC led to contradictory pronouncement ranging from "no long term effects" to "effects that may last for generations to come". There is almost no current data on the prevalence of tuberculosis, cancers, infertility and birth defects among the exposed population, all of which are reported by doctors to be on the rise involved in treatment of the survivors. However, to review the long-term MIC-effect 32 years after disaster it is mandatory to consider the environment, source of drinking water, socio-economic changes, life-style, history of morbidity, demographic changes, etc. and correlation with genetic instability for extraction of the residual effect and its transmission through generations.

\section{Long-Term Health Effects and Future Perspectives}

Lesson learned from the past mistake witnessed in catastrophic Bhopal accident has cautioned the developing countries for implementation of safety regulations alongside concurrent industrial developments. The disaster in UCC's pesticide manufacturing unit in Bhopal demonstrated local problem of industrial pollution and hazards 
Citation: Ganguly BB, Mandal S, Kadam NN. (2017) Genotoxic and Carcinogenic Effects of Methyl Isocyanate (MIC) Reviewed on Exposed Bhopal Population and Future Perspectives for Assessment of Long-Term MIC-Effect. J Environ Anal Toxicol 7: 452. doi: 10.4172/21610525.1000452

Page 6 of 10

are also linked to global market matrix. Three decades post-disaster, understanding the key issues of health-determinants in a complex scenario of living environment and life-style will direct sketching up policies and programs for strengthening and uplifting the children of the present and future generation [62,63]. The story of MICdisaster and the related health index needs to be resolved. Apart from fragmented and unplanned studies, which failed to generate convincing report, lack of consolidated health reports on different key parameters, especially genetic alteration, incidence of cancer and cancer-related mortality, and child health and morbidity puts a responsibility to conclude the long-term effect of MIC on exposed population and their offspring. However, the issue is highly critical due to unavailability of pre-MIC baseline information on the population, and also complex due to interaction of life-style, exposure, nutrition, and ageing over a period of three decades. Nevertheless, individual genetic make-up and variable susceptibility and morbidity may contribute to a great degree of variation in health outcome. Moreover, there could be bias in recalling health status and reproductive outcome, especially miscarriages, over such a long period. Thus, for charting the present health condition of the victims and their descendants, some of the key issues must be considered. Collectively, health survey, including genetic changes, birth defects and cancer-related mortality shall be measured at least annually as implemented for Hiroshima-Nagasaki survivors [64].

\section{Deficiencies in earlier reports and future direction}

Approximately 600,000 persons were exposed to MIC in Bhopal, of which $30 \%$ are estimated to be suffering from long-term health effects. Despite inflammatory damage to the eyes and lungs contributing to chronic morbidity resulting in opacity and stressful respiration, pregnancy loss, birth defects and genetic damage reported in victims were of serious concern. For a disaster of this magnitude, there is a relative paucity of medical information, as very little information has been published on the late recovery period, a phase in which the detection of chronic and long-term effects would be vital.

During the early phase following the accident, the major priority was to provide medical management to the victims over planning of epidemiological studies. The studies conducted by ICMR or other institutions had failed to establish causal relationship owing to defects in study-design including validity and precision of exposure and outcome variables, selection of study and control groups, etc., resulting in a significant bias (case selection, recall, small sample size, etc). If exposure was classified based on location of residence, some degree of misclassification was expected because it was not known that the person was actually exposed or not. Address and coding errors would have increased such misclassification. Socioeconomic differences between areas might also have affected the cancer incidence. Mehta et al. [65] rightly mentioned that 'bias was pervasive and there was insufficient information to allow careful operational definition of crucial matters, such as criteria for inclusion and exclusion of controls, and effects of independent and dependent variables on study outcome'. Koplan et al. [66] suggested that epidemiologic studies following disasters should accurately establish dose-response relationship which would be useful in identifying exposed and ill persons and determining longterm effects. Selection of cohort was recommended by Betrazii [67] for epidemiological studies rather than use of a population registry to avoid two major biases: (1) dilution of exposure prevalence and (2) selective migration of people from the disaster area. Some of the Bhopal population might have left Bhopal forever immediately after the disaster, thus resulting in dilution of exposure prevalence in the selected cohort.
The issues of study design and analysis by stratification of study population, random selection of subjects, blinding of investigators to exposure status and use of personal exposure measure would have increased the accuracy of exposure estimation $[68,69]$. Self reported data was expected to be more reliable to reconstruct the individual exposure level. The authors concluded that despite the time elapsed since accident and the potential for recall bias; it might be possible to estimate individual exposure in the survivors with some degree of accuracy. Use of exposure strata would be meaningful for sampling in future epidemiologic investigation for MIC-community of Bhopal. Exposure-stratified sampling techniques might provide valid estimates of exposure-response without including the total exposed community [6]. ICMR surveys indicated that the exposed population for the most part was residing in their homes where they lived in at the time of exposure in 1984. However, this condition needs verification and confirmation from the ration card, voter card, ICMR card number and personal-exposure history since in- and out-migration has created mixing of population after the disaster. Exposure-based stratified random sampling would also minimize bias that results from selfselection and exposure misclassification, and it would enable doseresponse and interaction relationships to be understood.

\section{Passive attack from more chemicals dumped at UCIL-Bhopal site}

Pre-disaster, several tons of obsolete pesticides and process wastes of UCIL were contaminating the surroundings of the factory and strewn into open drains, which rendered Bhopal city a dangerous place to live. Immediately after MIC-disaster, the Union Carbide factory was closed and pipes, drums and tanks were cleaned and sold, except the MIC, Sevin plants and storages of different residues. The leftover load of MIC and other hazardous chemicals was dumped in the factory site, which is contaminating soil and underground water till date. Chemicals, including naphthol, naphthalene, Sevin, alpha naphthol, tarry residue, mercury, volatile organo-chlorine compounds, chromium, copper, nickel, lead, chloroform, hexachloroethane, hexachlorobutadiene, and the pesticide $\mathrm{HCH}$ (BHC) and volatile halo-organics are left in UCIL site leading to continuous leakage resulting in pollution of the groundwater through percolation. Studies made by Greenpeace and others from soil, groundwater, well-water and vegetables from the residential areas around UCIL and from the factory site show contamination with a higher range of toxic heavy metals, solvents and a wide range of other chemical compounds. Among the hazardous waste in the plant site soil, heavy metals such as mercury, chromium, copper, nickel, lead as well as organochlorine compounds were persistent (Figure 1). Many of these chemicals have been demonstrated as potent cancinogens. Also trichloroethylene is known to impair fetal development at 50 times above safety limits specified by the United States Environmental Protection Agency (EPA) [47]. Several broadcasting media reported that the site is contaminated with 'thousands' of metric tons of toxic chemicals, held in open containers or loose on the ground.

Elevated levels of volatile chloroform, carbon tetrachloride and chlorobenzenes were also demonstrated in drinking (underground well) water [17]. UCC's laboratory tests in 1989 revealed that soil and water samples collected from near the factory and inside the plant were toxic to fish. The poor socio-economic group residing in the vicinity of the UCIL factory was dependent on underground water both for drinking and other domestic uses. In 1991, the municipal authorities declared water from over 100 tube wells to be unsafe for drinking and were abandoned. Well and groundwater in the surrounding areas tested in 1999 showed mercury levels to be at "20,000 and 6 million times" 
Citation: Ganguly BB, Mandal S, Kadam NN. (2017) Genotoxic and Carcinogenic Effects of Methyl Isocyanate (MIC) Reviewed on Exposed Bhopal Population and Future Perspectives for Assessment of Long-Term MIC-Effect. J Environ Anal Toxicol 7: 452. doi: 10.4172/21610525.1000452

Page 7 of 10
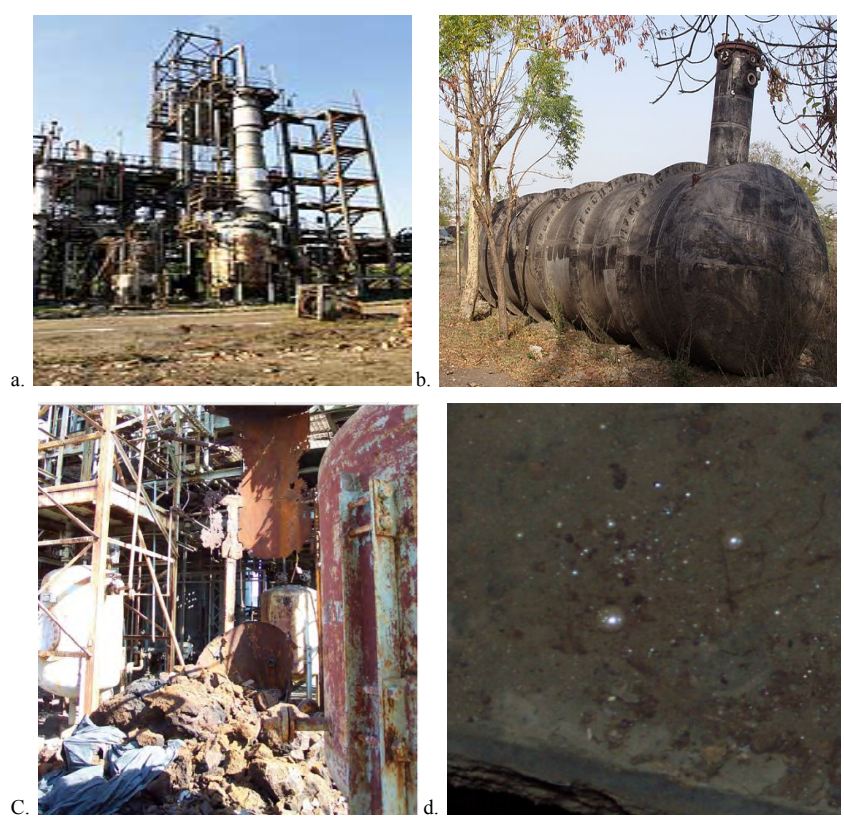

Figure 1: Post-disaster Union Carbide India Limited at Bhopal: a. UCIL factory b. MIC-storage tank 610; c. left-over of unused chemicals; $d$. mercury droplets.

higher than expected levels. A sample of drinking water from a well near the UCIL site had 500 times higher levels of contamination than the maximum limits recommended by the World Health Organization (WHO). Many of these chemical contaminants were also found in breast milk. Underground water was the major source of irrigation for agriculture in the vicinity. Therefore, consumption of agricultural produces in these affected areas might have doubled the burden of chemical consumption by the residents. In addition, use of and exposure to pesticides may interact with other toxic substances in vivo physiological system among the gas-victims.

\section{Assessment of present genetic condition}

The interaction of biological and non-biological factors are of major concern for adjustment of MIC effect and tracking the cause of present health status 32 years post MIC-disaster. There are changes in the environmental admixture and population composition due to in and out migration. At this moment it is difficult to ascertain the health effects to exposure level of MIC in different individuals. Both in the environment as well as in human body, it is apparent that MIC-effect has been diluted through natural and physiological reactions. Thus, it would be justified to consider a second control (migrated) group who were not exposed to MICaccident in 1984 but living in the same affected areas for 20-25 years, to estimate the effects of MIC and other chemicals through soil and ground and well-water. Screening of this migrated control group will extract the effect of soil and water contaminations with leftover chemicals in the UCIL site and accurately adjust the long-term effect of MIC. Therefore, detail residential and occupational history will be crucial for both MIC-exposed, unexposed and migrated controls. Explicit information on residence (environmental condition), health status, life-style and occupational history, including changes in work place, type of work, and occupational and environmental exposure to hazardous chemicals, gas or radiation shall be recorded in time-scale of five-ten years interval.

A detailed health and outcome information could be collected from three generations. Since 1984, there are two different types of families, such as

1. In 1984, if men of 25-30 years and women of 20-25 years (child bearing age) were exposed and survived, they are 55-60 years old and 50-55 years old respectively after 30 years, and they can have male and female children of 20-25 years and grandchildren of 1-5 years old (at least one).

11. Individuals with exposure at pre-adolescent age (10-12 years) have become parents of 10-20 years old children after 30 years.

Pedigree chart will record whether both partners were exposed or one was from unexposed control zone or from different town, and if consanguinity was there. It is expected that there will be minimum of five members in each family, including parents of first generation (FI) who were exposed at child-bearing age, parents of second generation (FII) who were exposed in childhood, in utero or conceived after disaster-exposure and offspring of the third generation (FIII), at least one. However, all the parents of the two generations may not be alive, and there can be more than one member in FIII generation.

\section{Potential confounders}

Study of long term effect of MIC after 32 years of the disaster would encounter with a number of confounding factors, more prominently recall of health history since 1984, maintenance and retrieval of health records, history on life-style (tobacco consumption in smoking, chewing and other form), change of residence, change of job, socioeconomic condition (especially nutrition status), source of water for domestic use, soil and water contamination with chemical wastes from Union Carbide factory, etc. The issue of socioeconomic condition on health status following MIC exposure would be a major confounder Other obvious factors such as ambient air pollution, immune status, and psychological fear would also have some interaction on genetic consequences. Although, the local residents are currently living in concrete houses, there is hardly any window to allow fresh air for breathing inside (Figure 2). The open drains in the residential area are carrying the sewage of domestic excrete and small-scale cottage production. There is ample opportunity of contaminating the water pipes if fitted through and submerged in the drains. Recall of occupational history and occupational exposure to genotoxic agents would also be confounding significantly. Recall of pubertal development and reproductive outcome would be difficult for the FI parents. Age of the FI parents, maternal age at conception, number of conception, use of medicines since 1984, etc. would be potential confounders for health assessment of MIC-exposed population. Control of confounders shall consider the study design phase (randomization and sufficient sample size, uniform criteria/questionnaire for selection of study subjects and technical design for estimation of long-term genetic effects (dependent and independent variables). Further, stratification of data shall depend on aging, morbidity and their mutual interaction for leading to agerelated disease-onset. Aging is a significant biological confounder 32 years post disaster for the MIC-exposed population. Aging is associated with increase in CA, SCE, MN and delayed cell cycle [70-73].

To some extent, the variables can be controlled on comparison of then genetic alterations with the current state. It is noteworthy that information of the multi-center genetic survey following the accident in 1984 has not been published. Retrieval of the records from the archive and analysis will definitely present scenario of genetic damage immediately post-exposure from different degrees of exposure. It is also worthy to mention that a similar exercise on conventional cytogenetic investigation on exposed and unexposed individuals is underway. 
Citation: Ganguly BB, Mandal S, Kadam NN. (2017) Genotoxic and Carcinogenic Effects of Methyl Isocyanate (MIC) Reviewed on Exposed Bhopal Population and Future Perspectives for Assessment of Long-Term MIC-Effect. J Environ Anal Toxicol 7: 452. doi: 10.4172/21610525.1000452

Page 8 of 10
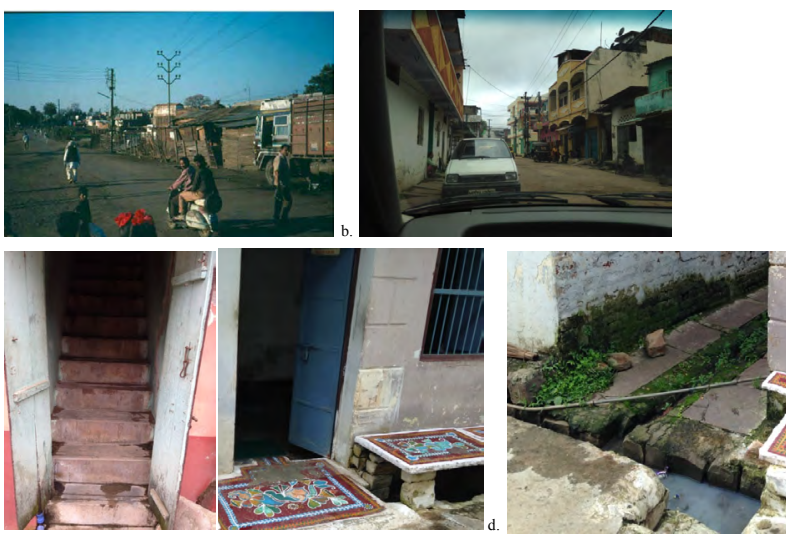

Figure 2: Pre- and post-MIC habitats around UCIL: a. Thatched huts of 1984; b. Present-day residences; c. dark interior of houses with no free flow of air or light; d. drains and water connection.

Briefly, Giemsa (G)-banding karyotyping has identified constitutive abnormalities, and also translocations and hyperdiploid conditions specific to hematopoietic malignancies such as $\operatorname{del}(5 \mathrm{q})$, trisomy 8 , etc. in some individuals (unpublished data). However, generation of a comparative result may take some time to talk on the long-term effects of MIC on MIC-victims.

\section{Conclusion}

The immediate screening of genetic damage in the MIC-exposed survivors was carried out by six institutions under the supervision of ICMR; however, the result was made unavailable to public till date. Individual reports have projected overestimation of genetic aberrations as indicated in aberrant images. After three decades, the issue of longterm effect of MIC has been raised, and thus, an approach has been undertaken for screening of genetic condition of Bhopal population, which is under progress. With a view to rationalizing the concept of genetic screening, this review has been raised on the spectrum of health-condition over the three decades post-exposure amidst complex biological and environmental consequences. Incidences of the cancer-burden and chronic kidney disease have been demonstrated increased; however, it cannot directly be linked to MIC-exposure since multiples of compounding factors such as life-style, living environment, nutritional factor, occupational exposure, and inherent genetic condition are interacting. Nevertheless, delayed effect cannot be ruled out since latency period of chemical exposure and perturbation of biological and immune system may contribute to delayed expression. The confounding factors and its control shall be paid importance while screening long-term effects of chemical exposure in any population. Nevertheless, biological aging will render significant health-effect in elderly population.

\section{Acknowledgements}

The authors wish to acknowledge financial support of Indian Council of Medical Research, India

\section{Conflict of Interest}

Nothing to declare.

\section{References}

1. Willey RJ (2010) Book Review, 25 Years Later: The largest industrial disasters with hazardous material. Appeared in the Safety \& Health Newsletter of the American Institute of Chemical Engineers (AIChE), Pietersen, Gelling

\section{Publishing Co, The Netherlands.}

2. ICMR Technical Report (2008) Technical report on Population based long term clinical studies. In: Sriramachari S. Health effects of the toxic gas leak from Union Carbide methyl isocyanate plant in Bhopal (1984-1992). Indian Council of Medical Research, New Delhi, India.

3. Bhandari NR, Syal AK, Kambo I, Nair A, Beohar V, et al. (1990) Pregnancy outcome in women exposed to toxic gas at Bhopal. Indian J Med Res 92: 28-33.

4. Broughton $E$ (2005) The Bhopal disaster and its aftermath: a review. Environ Health 4: 6.

5. Dhara R (1992) Health effects of the Bhopal gas leak: a review. Epidemiol Prev 14: 22-31.

6. Dhara VR, Dhara R, Acquilla SD (2002) Personale-exposure and long-term health effects in survivors of the Union Carbide Disaster at Bhopal. Environ Health Perspect 110: 487-500.

7. Ganguly BB (1993) Aftermath of MIC disaster. Science Courier 8: 24-25.

8. Willey RJ, Hendershot DC, Berger S (2007) The accident in Bhopal: Observations 20 years later. Process Saf Prog. 26: 180-184.

9. Talukder G, Sharma A (1989) The Bhopal accident: it's after effects. In Majumdar SK, Miller EW, Schmalz RF. Management of Hazardous Materials and Wastes. Pennsylvania Academy of Science Publication, Easton, PA, pp 409-417.

10. Mangla $B$ (1989) Long-term effects of methyl isocyanate. Lancet 2: 103.

11. Kimmerle G, Eben A (1964) On the Toxicity of Methylisocyanate and Its Quantitative Determination in the Air. Arch Toxikol 20: 235-241.

12. Varma DR (1987) Epidemiology and experimental studies on the effect of methyl isocyanate on the course of Pregnancy. Environ Health Perspect 72 : 153-157.

13. Varma DR (1991) Pregnancy complications in Bhopal women exposed to methyl isocyanate vapor. J Environ Sci Health 26: 1437-1447.

14. Bang R, Sadgopal M (1990) Effect of Bhopal disaster on women's health: an epidemic of gynecological diseases. In: Distorted Lives: Women's Reproductive Health and Bhopal Disaster. Part I. Medico Friend Circle.

15. Schwetz BA, Adkins B Jr, Harris M, Moorman M, Sloane R (1987) Methy isocyanate: Reproductive and developmental toxicology studies in Swiss mice. Environ Health Perspect 72: 149-152.

16. Kapoor R (1991) Fetal loss and contraceptive acceptance among the Bhopa gas victims. Soc Biol 38: 242-248.

17. Labunska I, Stephenson A, Bridgen K (1999) Toxic contaminants at the former Union Carbide Factory site, Bhopal, India: 15 yrs after the Bhopal accident Exeter, UK: Greenpeace Research Laboratories, Dept. of Biological Sciences University of Exeter.

18. Varma DR, Ferguson J, Alarie $Y$ (1990) Dissociation between maternal and feta toxicity of methyl isocyanate in mice and rats. J Toxicol Environ Health 30: 1-14.

19. EHP (1987) Environmental Health Perspectives 72.

20. Brown WE, Green AH, Cedel TE, Cairns J (1987) Biochemistry of ProteinIsocyanate Interactions: A Comparison of the Effects of Aryl vs. Alky Isocyanates. Environ Health Perpect 72: 5-11.

21. Karol MH, Taskar S, Gangal S, Rubanoff BF, Kamat SR (1987) The antibody response to methyl isocyanate: An experimental and clinical findings. Eviron Health Perspect 72: 169-175.

22. Srivastava R (2011) Bhopal gas disaster: Review on health effects of methyl isocyanate. Res J Environ Sci 5: 150-156.

23. ICMR Technical Report (2010) Histopathological and Experimental Studies. Technical report on Pathology and Toxicology. In: Sriramachari S (ed) Health effects of the toxic gas leak from Union Carbide methyl isocyanate plant in Bhopal (1984-1992). Indian Council of Medical Research, New Delhi, pp 24-28.

24. EHC (1985) Environmental Health Criteria 46. Guidelines for the study of genetic effects in human populations. World Health Organization, Geneva.

25. Carrano AV, Natarajan AT (1988) International Commission for Protection Against Environmental Mutagens and Carcinogens. ICPEMC publication no. 14. Considerations for population monitoring using cytogenetic techniques. Mutat Res 204: 379-406. 
Citation: Ganguly BB, Mandal S, Kadam NN. (2017) Genotoxic and Carcinogenic Effects of Methyl Isocyanate (MIC) Reviewed on Exposed Bhopal Population and Future Perspectives for Assessment of Long-Term MIC-Effect. J Environ Anal Toxicol 7: 452. doi: 10.4172/2161 0525.1000452

26. Ghosh BB, Sengupta S, Roy A (1990) Cytogenetic studies in human populations exposed to gas leak at Bhopal. Environ Health Perspect 86: 323-326.

27. Goswami HK (1986) Cytogenetic effects of methyl isocyanate exposure in Bhopal. Hum Genet 74: 81-84.

28. Deo MG, Gangal S, Bhisey AN, Somasundaram R, Balsara B, et al. (1987) Immunological, mutagenic \& genotoxic investigations in gas exposed population of Bhopal. Indian J Med Res 86 Suppl: 63-76.

29. Saxena AK, Singh KP, Nagle SL, Gupta BN, Ray PK, et al. (1988) Effect of exposure to toxic gas on the population of Bhopal: Part IV-Immunological and chromosomal studies. Indian J Exp Biol 26: 173-176.

30. Ghosh BB, Talukder G, Sharma A (1991) Frequency of chromosome aberrations induced by trimethyltin chloride in human peripheral blood lymphocytes in vitro: Related to age of donors. Mech Age Develop 57: 125-137.

31. Mason JM, Zeiger E, Haworth S, Ivett J, Valencia R (1987) Genotoxicity studies of methyl isocyanate in Salmonella, Drosophila, and cultured Chinese hamster ovary cells. Environ Mutagen 9: 19-28.

32. Conner MK, Rubinson HF, Ferguson JS, Stock MF, Alarie Y (1987) Evaluation of sister chromatid exchange, and cytotoxicity in murine tissue in vivo and Lymphocytes in vitro following methyl isocyanate exposure. Environ Health Perspect 72: 177-182.

33. Tice RR, Luke CA, Shelby MD (1987) Methyl isocyanate: An evaluation of in vivo cytogenetic activity. Environ Mutagen 9: 37-58.

34. Kligerman D, Campbell JA, Erexson GL, Allen JW, Shelby MD (1987) Sister chromatid exchange analysis in lung and peripheral blood lymphocytes of mice exposed to methyl isocyanate by inhalation. Environ Mutagen 9: 29-36.

35. Shelby, MD, Allen JW, Caspary WJ, Haworth S, Ivett J, et al. (1987) Results of in vitro and in vivo genetic toxicity tests on Methyl Isocyanate. Environ Health Perspect 72: 183-187.

36. Meshram GP, Rao KM (1988) Cytogenetic activity of methyl isocyanate in vivo in the mouse micronucleus test. Toxicol Lett 42: 65-71.

37. Tamura N, Aoki K, Lee MS (1992) Selective reactivities of isocyanates towards DNA bases and genotoxicity of methylcarbamoylation of DNA. Mutat Res 283 97-106.

38. Goswami HK, Chandorkar M, Bhattacharya K, Vaidyanath G, Parmar D, et al. (1990) Search for chromosomal variations among gas-exposed persons in Bhopal. Hum Genet 84: 172-176.

39. Das BC (1991) Cytogenetic studies on MIC gas exposed persons in Bhopal. Hum Genet 87: 513.

40. Mishra PK, Bhargava A, Raghuram GV, Jatawa SK, Akhtar N, et al. (2009) Induction of genomic instability in cultured human colon epithelial cells following exposure to isocyanates. Cell Biol Int 33: 675-683.

41. Malla TMD, Senthilkumar CS, Sharma NC, Ganesh N (2011) Chromosome Instability Among Bhopal Gas Tragedy Survivors. American-Eurasian J Toxicological Sciences 3: 245-249.

42. Senthilkumar CS, Akhter S, Malla TM, Sah NK, Ganesh N (2015) Increased Micronucleus Frequency in Peripheral Blood Lymphocytes Contributes to Cancer Risk in the Methyl Isocyanate-Affected Population of Bhopal. Asian Pac J Cancer Prev 16: 4409-4419.

43. Dikshit RP, Kanhere S (1999) Cancer patterns of lung, oropharynx and ora cavity cancer in relation to gas exposure at Bhopal. Cancer Causes Control 10: $627-636$.

44. National Cancer Registry Programme (2010) Cancer in Bhopal: Comparision of cancer pattern in MIC affected and unaffected areas (1988-2007). Indian Council of Medical Research, Banglore, India.

45. ATSDR (2003) Agency for Toxic Substances and Disease Registry.

46. IARC (1987) IARC Monographs on the Evaluation of Carcinogenic Risks to Humans, Supplement 6, Genetic and Related Effects: An Updating of Selected IARC Monographs from Volumes 1-42. International Agency for Research on Cancer, Lyon.

47. US-EPA (1986) Health and Environmental Effects Profile for Methyl Isocyanate. U. S. Environmental Protection Agency. Environmental Criteria and Assessment Office, Office of Health and Environmental Assessment. Cincinnati: Office of Research and Development.
48. Ganguly BB, Kadam NN (2016) Mutations of myelodysplastic syndromes (MDS): An update. Mutat Res 769: 47-62.

49. Ganguly BB, Dolai TK, De R, Kadam NN (2016) Spectrum of complex chromosomal aberrations in a myelodysplastic syndrome and a brief review. J Can Res Ther 12: 1203-1206

50. Ganguly BB, Mandal S, Kadam NN, Banerjee D, Chandra S, et al. (2016) Experience of Conventional Cytogenetics in Elderly Cytopenic Indian Patients Suspected with Myelodysplastic Syndromes. Blood 128: 5488.

51. Tucker AN, Bucher JR, Germolec DR, Silver MT, Vore SJ, et al. (1987) Immunological Studies on Mice Exposed Subacutely to Methyl Isocyanate. Environ Health Perspect 72: 139-141.

52. Karol MH, Kamat SR (1987) The antibody response to methyl isocyanate: Experimental and clinical findings. Bull Eur Physiopathol Respir 23: 591-597.

53. Varma DR, Mullay S (2015) Methyl isocyanate: The Bhopal Gas. In: Gupta RC (ed) Handbook of Toxicology of Chemical Warfare Agents ( $2^{\text {nd }}$ Edn). Elsevier pp 287-300.

54. Saxena AK, Paul BN, Sinha M, Dutta KK, Das SN, et al. (1991) A study on the $B$ cell activity in protein deficient rats exposed to methyl isocyanate vapour. Immunopharmacol Immunotoxicol 13: 413-424.

55. Dwivedi PD, Mishra A, Gupta GS, Dutta KK, Das SN, et al. (1988) Inhalation toxicity studies of methyl isocyanate (MIC) in rats: Part IV--Immunologic response of rats one week post exposure: Effect on body and organ weights, phagocytic and DTH response. Indian J Exp Biol 26: 191-194.

56. Pearson PG, Slatter JG, Rashed MS, Han DH, Grillo MP, et al. (1990) S-(Nmethylcarbamoyl)glutathione: a reactive $\mathrm{S}$-linked metabolite of methyl isocyanate. Biochem Biophys Res Commun 166: 245-250.

57. Slatter JG, Rashed MS, Pearson PG, Han DH, Baillie TA (1991) Biotransformation of methyle isocyanate in the rat. Evidence of glutathione conjugation as a major pathway of metabolism and implications for isocyanatemediated toxicities. Chem Res Toxicol 4: 157-161.

58. National Toxicology Program (1986) The toxicity of methyl isocyanate. Environ Health Perspect 72: 1-200.

59. Yoon JY, Oh SH, Yoo SM, Lee SJ, Lee HS, et al. (2001) N-nitrosocarbofuran but not carbofuran, induces apoptosis and cell cycle arrest in $\mathrm{CHL}$ cells. Toxicology 169: 153-161.

60. Hagmar L, Stromberg U, Welinder H, Mikoczy Z (1993) Incidence of cancer and exposure to toluene diisocyanate and methylene diphenyldiisocyanate: $A$ cohort based case-reference study in the polyurethane foam manufacturing industry. Br J Ind Med 50: 1003-1007.

61. Kuo HH, Shyu SS, Wang TC (2008) Genotoxicity of low dose N-nitroso propoxur to human gastric cells. Food Chem Toxicol 46: 1619-1626.

62. Ganguly BB, Kadam NN (2015) Health of the underprivileged children: A close look into a subset of tribal group and street population of India. New Ind J Ped 4: 156-166.

63. Ganguly BB, Kadam NN (2016) Understanding Social Determinants for Children in Difficult Circumstances: An Indian Perspective. Int J Ped Child Health 4: (In Press).

64. Douple EB, Mabuchi K, Cullings HM, Preston DL, Kodama K, et al. (2011) Long-term Radiation-Related Health Effects in a Unique Human Population: Lessons Learned from the Atomic Bomb Survivors of Hiroshima and Nagasaki. Disaster Med Public Health Prep 5: S122-S133.

65. Mehta PS, Mehta AS, Mehta SJ, Makhijani AB (1990) Bhopal tragedy's health effects. A review of methyl isocyanate toxicity. JAMA 264: 2781-2787.

66. Koplan JP, Falk H, Green G (1990) Public health lessons from the Bhopa chemical disaster. JAMA 264: 2795-2796.

67. Bertazzi PA (1989) Industrial disasters and epidemiology. A review of recent experiences. Scand J Work Environ Health 15: 85-100.

68. Dhara VR, Kriebel D (1993) An exposure-response method for assessing the long term health effects of the bhopal gas disaster. Disasters 17: 281-290.

69. WHO (1997) Assessing the health consequences of major chemical incidents epidemiological approaches. World Health Organization, European Series, No. 6. 
Citation: Ganguly BB, Mandal S, Kadam NN. (2017) Genotoxic and Carcinogenic Effects of Methyl Isocyanate (MIC) Reviewed on Exposed Bhopal Population and Future Perspectives for Assessment of Long-Term MIC-Effect. J Environ Anal Toxicol 7: 452. doi: 10.4172/21610525.1000452

70. Ganguly BB (1993) Cell division, chromosomal damage and micronucleus formation in peripheral lymphocytes of healthy donors: Related to donor's age. Mutat Res 295: 135-148.

71. Ganguly BB (1993) Cell division, chromosomal aberration and micronucle formation in human peripheral blood lymphocytes: Effect of stannic chloride on donor's age. Biol Trace Element Res 38: 55-62.
72. Ganguly BB (1995) Age related variation in sister chromatid exchanges and cel cycle kinetics in peripheral blood lymphocytes of healthy individuals. Mutat Res (DNAging) 316: 147-156

73. Ganguly BB (1995) Age related alterations in cell division and cell cycle kinetics in control and trimethyltin treated lymphocytes of human individuals. BioMetals 8: 263-269. 